$\operatorname{con} F \cdot 850671--18$

UCRL- 92229

PREPRINT

UCRL -92229

DE85 012971

\title{
PRELIMINARY EVALUATION OF ALTERANT GEOPHYSICAL \\ TOMOGRAPHY IN WELDED TUFF
}

\begin{abstract}
A. L. Ramirez
W. D. Daily
\end{abstract}

This paper was prepared for submittal to the 26th U.S. Symposium on Rock Mechanics, Rapid City, South Dakota, June 26-28, 1985.

February, 1985

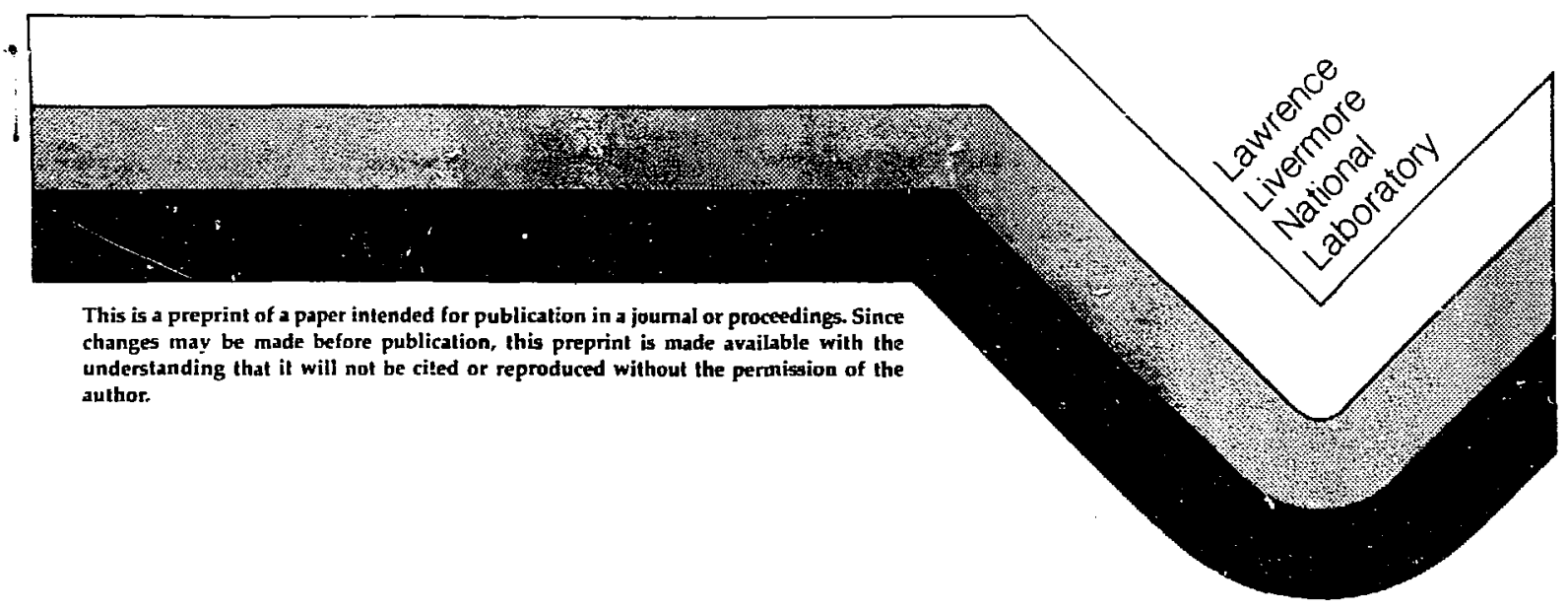


Preliminary evaluation of alterant geophysical tomography in welded t.uff

A. L. Ramirez and W. D. Daily

Lawrence Livermore National Laboratory, Livermore, USA

\section{ABSTRACT}

The ability of alterant geophysical tomography to delineate flow paths in a welded tuff rock mass has been preliminarily evaluated based on the results of a field experiment. Electromagnetic measurements were made before, during and after a water-based, dye tracer flowed through the rock mass. Alterant geophysical tomegraphs were generated and compared with independent evidence -- borescope logs, neutron logs and dyed rock samples. Anomalies present in the tomograph match the location and orientation of fractures mapped with a borescope. The location of tracer-stained fractures coincides with the location of some image anomalies; other geophysical anomalies exist where tracer-stained fractures were not observed, perhaps due to poor core recovery. Additional drilling to locate stained flow paths and other experiments are planned so that the applicability of the technique can be further evaluated.

\section{INTRODUCTION}

The Nevada Nuclear Waste Storage Investigations (NNWSI) Project is studying the suitability of the tuffaceous rocks at Yucca Mountain, Nevada Test site, for the construction of a high-level nuclear waste repository. Lawrence Livermore National Laboratory (LLNL), Livermore, California, has been given the tasks of evaluating the waste package environment and designing and verifying the performance of waste packages for the NNWSI Project.

Various in-situ tests will be conducted within the Topopah Springs member of the Paintbrush Tuff at Yucca Mountain to investigate its behavior in the vicinity of simulated waste packages. The planned tests will simulate the waste package by emplacement of heater? within the rock mass. Rock behavior will be monicored during the heatin, and cooling phases and with water percolating through the rock mass.

A possible hydrologic scenario that could develop around a heater is shown schematically in Figure 1. The heater will dehydrate the partially saturated rock near the emplacement borehole. The water vapor formed will travel thru the matrix until it intersects a fracture and then moves aiong the fracture. The water vapor 


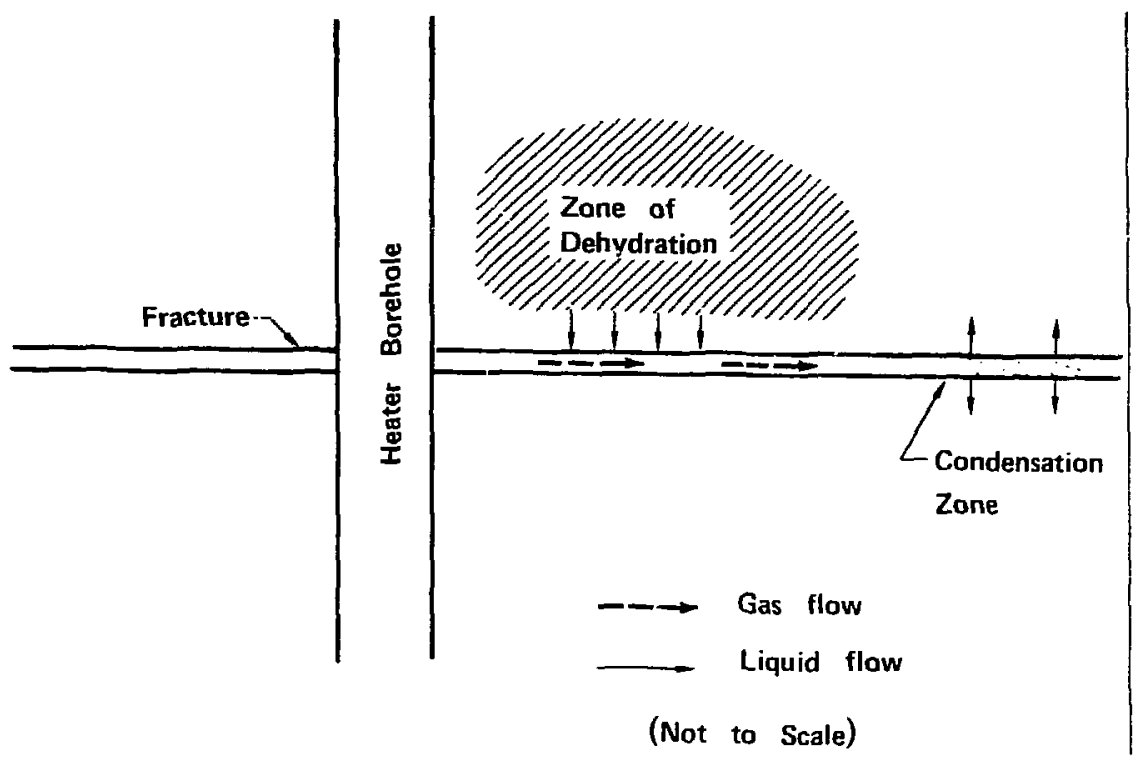

Figure 1. Schematic diagram of a possible hydrologic scenario around a heater in partially saturated, welded tuff.

condenses where the temperatures are sufficiently cool. Part of this water may move into the matrix due to capillary action while the remainder may flow along the fracture. When the heater is turned off, the dehydrated region is expected to slowly resaturate.

The hydrologic behavior of the near field waste package environment will be studied with various measurement techniques (Yow, 1985). This paper discusses the preliminary results of an experiment in which one of the candidate measurement techniques, alterant geophysical tomography, (Ramirez and Lytle, 1984) was evaluated. In this particular experiment, our objective was to evaluate the capacity of alterant tomography to distinguish between water within a fracture and the much larger volume of water trapped in the surrounding welded tuff. Additional work is required to investigate the method's effectiveness in resolving the remaining components of hydrologic behavior shown in Figure 1 .

\section{DESCR IPTION OF EXPERIMENTS}

For this study, we used measurements of very high frequency (VHF) electromagnetic waves having a frequency of $300 \mathrm{MHz}$. The region between the boreholes was divided into many cells and an attenuation rate is calculated for each cell from line integral equations which can be written for each ray path. This set of equations can be solved iteratively using various reconstruction algorithms (Lager and Lycle, 1977). The quantity of interest in this study is the attenuation rate (defined as the inverse of the distance along which the signal is attenuated by a factor of $1 / e$ ). 
Rock mass electromagnetic attenuation rate is a sensitive function of (among other things) water content of the rock (Poley, et al., 1978; Daily and Ramirez, 1984). Typically, the larger the water content, the larger the attenuation rate. In Figure 1, water condensing in the fracture dill change the attenuation rate. In this experiment, we used a water tracer to change the attenuation rate of the fractures accepting the tracer.

Water trapped in the rock matrix needs to be distinguished from water filling a fracture. We used a technique known as alterant geophysical tomography where measurements are made before and after a water tracer is added to the rock. The image formed by subtracting values of corresponding cells of the "before" and "after" tomographs is the alterant tomograph. Rock influenced by the tracer is represented in the alterant image by the changes in attenuation rate. Thus, alterant tomograph might be useful to define changes in fracture saturation by distinguishing between water within fractures and invariable anomalies such as those caused by water trapped in the matrix.

The experiment was conducted in an ash flos tuff formation of the Grouse Canyon member of the Belted Range Tuff. This formation is readily accessible and is lithologically similar to that of the proposed repository horizon, the Topopah Spring tuff, at Yucca Mountain. The Grouse Canyon tuff is in the unsaturated zone but has a degree of saturation greater than 85 percent. Porosity ranges from 13 to 25 percent (Johnstone and Wolfsberg, 1980). Measurements were made between three parallel coplanar boreholes drilled 90 centimeters apart into the rib of the extensometer drift in the G-tunnel complex at the Nevada Test Site. Figure 2 shows the borehole layout relative to the drift. Boreholes 2,3 and 4 serve as measurement holes. Borehole 1 is drilled 2 degrees below horizontal to provide a reservoir from which water could infiltrate the rock. All boreholes are six meters long. This scale is similar to that planned for the waste package tests to be conducted in Yucca Mountain. Previous fracture mapping near this region of $G$ tunnel indicates that most fractures are roughly vertical with two predominant sets striking approximately $\mathrm{N} 40-60^{\circ} \mathrm{W}$ and $\mathrm{N} 20-40^{\circ} \mathrm{E}$. The azimuth of our measurement boreholes is $\mathrm{N} 15^{\circ} \mathrm{W}$.

Tomographs were made between holes 2 and 3 (referred as the upper measurement region) and between holes 3 and 4 (Lower measurement region). The tomographs image the region along the holes between three anc six meter depth (measured laterally). All depth distances were measured from a reference lire just outside the hole collars. Initial measurements between boreholes 2 and 3 and between 3 and 4 were made prior to the start of tracer flow. Inversions of these measurements provide the baseline attenuation factor geocomographs of the rock and ara designated as "before" measurements. Then borehole 1 was filled first with a solution of water and methylene chloride dye which stains the rock dark blue on contact. Several days later a second solution consisting of salted water and dye solution was added. Coring the rock mass was planned as the last part of the experiment to locate blue fractures and corroborate the tomographic data. Measurements were taken for the next two calendar weeks after adding water to borehole 1 , alternating each day between the upper and lower measurement regions. 


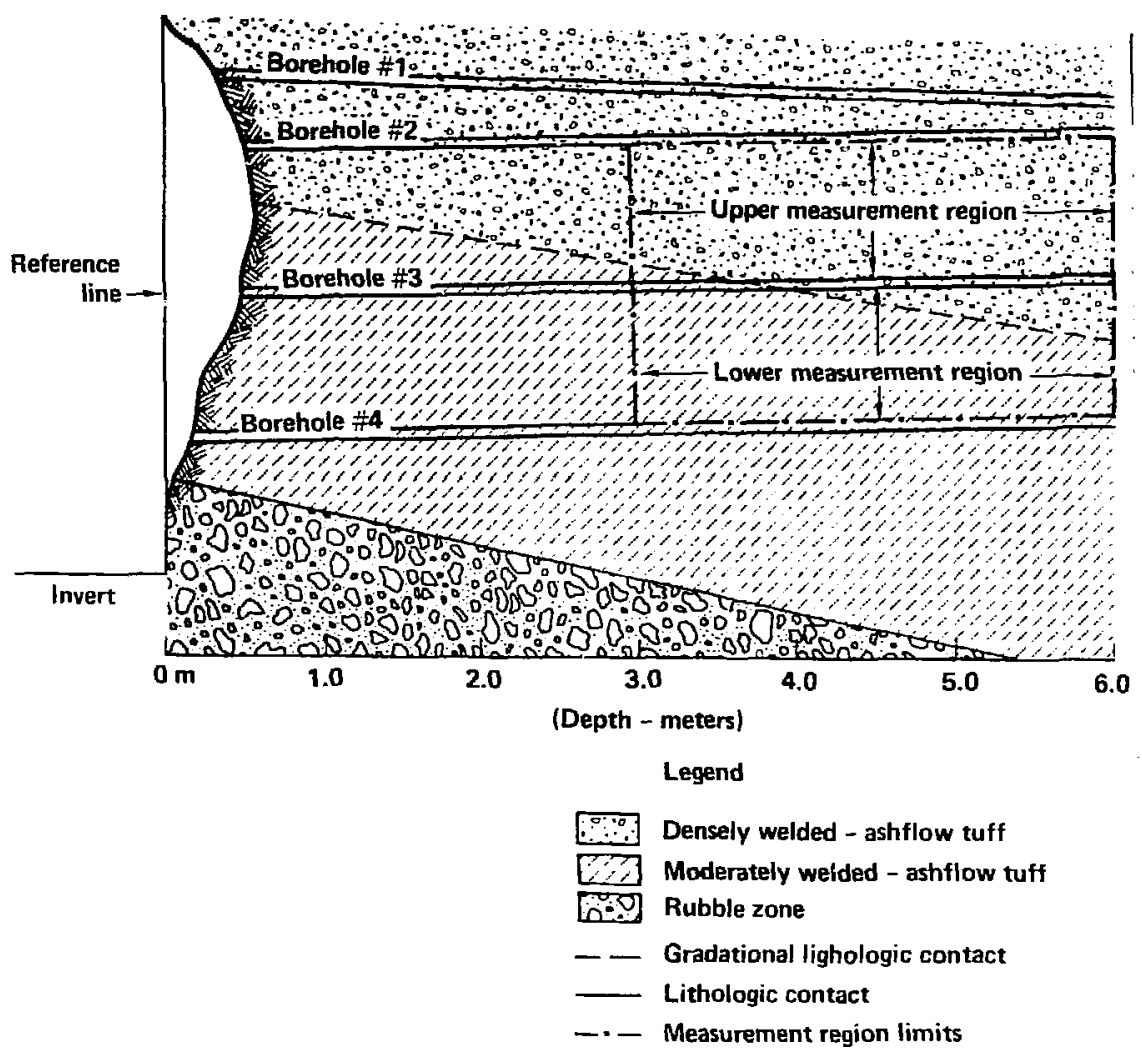

Firure 2. Borehole layout and tomographic plane relative to local geology (geology extrapolated from map by Langkopf and Eshom (1982) pp. 15-16).

Additional geophysical information on the rock mass was collected in an effort to verify our inferences from the tomographic data. Neutron surveys were made to obtain overall rock mass saturation in an attempt to locate those fractures which accepted water. These surveys were made in holes 2,3 , and 4 before the water was added to the formation and again after the geotomographic data was taken when water had been infiltrating the formation for more than two weeks. In addition, boreholes were cored in the plane of measurement to locate fractures stained by the blue dye and thus identify the location of those fractures which conducted water. Two holes ware cored between each of the three tomographic measurement holes after the tomographic data was collected. Also, a borescope was used to log fractures in holes 2,3 , and 4 , and the four post-experiment core holes. 


\section{RESULTS AND DISCUSSION}

Figure 3 presents alterant tomographs showing the changes in attenuation factors caused by salt water tracers along the upper measurement region. Unsalted tracers were also used; however portions of these data sets are inaccurate and are not shown. All images shown in this paper consists of an array of $7.5 \mathrm{~cm}$ square cells 40 rows long and 12 columns high. The gray scale represents the changes in attenuation factor with the dark grey tones corresponding to large changes. The images from both the upper and lower measurement regions, represent a combined region $180 \mathrm{~cm} \mathrm{high} \mathrm{and}$ $300 \mathrm{~cm}$ long.

Figure 3 shows the evolution of the image anomalies as the tracer penetrated farther into the rock mass. As expected, the anomalies in the top (early) tomograph show smaller changes in attenuation actor than the anomalies in the bottom (later) tomograph. The two vertical anomalies centered at depths of $3.4 \mathrm{~m}$ and $3.9 \mathrm{~m}$ could be fracture flow paths. This interpretation is consistent with geologic data (Langkopf and Eshom, 1982) that most of the fractures in this unit are vertical. A diagonal anomaly beginning at a depth of $4.0 \mathrm{~m}$ in borehole 3 is present in both cases. This anomaly suggests flow paths other than vertical in the rock mass and appears to grow with time.

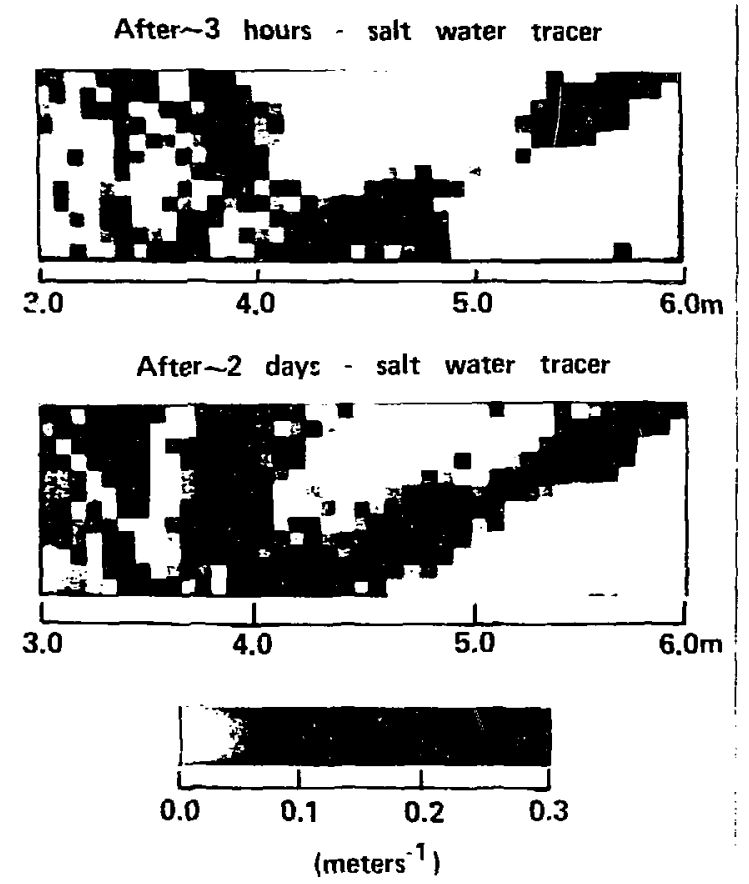

Figure 3. Altarant tomographs of the upper measurement region showing how the image anomalies changed as the tracer penetrated the rock mass. 
An important element controlling the reliability of the alterant tomographs shown in Fig. 3 is data noise. The relatively small changes shown by the images are obtained by subtracting two data sets consisting of relatively large numbers. Thus, slight errors in large numbers could account for some of the changes. We have estimated possible errors present in the data by comparing two data sets (subsequently used for tomographs) taken 16 hours apart while the rock mass properties remained constant. The differences between corresponding measurements were used as the error estimates. We then used computer simulations to investigate how these errors propagate in the alterant tomographs. In this manner, we have discarded anomalies which could have been associated with measurement error-

These "noise-free" (at a 99\% confidence leve1) results are shown in Figure 4b. The tomographs of the upper measurement region and the upper half of Figure $4 \mathrm{~b}$ in Figure 3 can be compared to evaluate the significance of random measurement noise. There are differences between these two tomographs. However, the major anomalies observed in Figure 3 can also be recognized in the upper half of Figure $4 b$. Thus, we suggest that the major anomalies in the tomograph are caused by factors other than data noise.

(a)

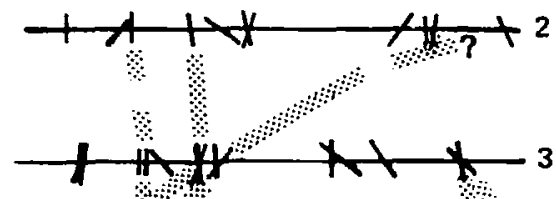

mos Possible flow path

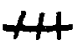
Fracture location and orientation in image area
3.0
4.0
5.0
$6.0 \mathrm{~m}$

(b)
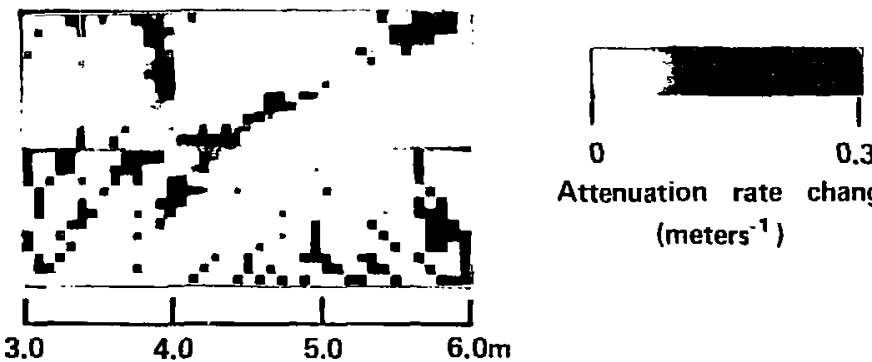

Attenuation rate change $\left(\right.$ meters $\left.^{-1}\right)$

Figure 4. Comparison of available fracture orientation data (a) and the final alterant tomograph (b) in which any changes likely to he associated with random measurement errors ( $99 \%$ confidence level) have been set to $0.0 \mathrm{~m}^{-1}$. Combining the borescope mapped fractures and the tomograph, possible flow paths have been postulated in (a). 
The alterant tomograph (Figure $4 \mathrm{~b}$ ) is compared with fractures mapped with a borescope (Figure 4a) along boreholes 2,3 , and 4. Both fracture locations and the apparent dip of the fracture along the plane of measurement are show (orientation data reliable to approximately $\pm 20^{\circ}$ ). The orientation of a few fractures in boreholes 2,3 , and 4 could not be determined and are not shown.

We have combined the fracture location and orientation data with the tomographic data to construct the model of possible flow paths in Fig. 4a. Several observations can be made based on Figure 4. Some of the postulated flow paths are discontinuous; i.e., flow is not fully contained in the tomographic plane. The postulated flow paths of the tracer are all associated with fractures (i.e., there is no evidence requiring matrix flow), but not all fractures serve as flow paths. Positive indications of the technique's effectiveness can be recognized in Figure 4. These are: a) the 1 ineal trends expected of fracture flow which are defined by the larger anomalies and b) the general agreement between the larger image anomalies in Fig. 4 and the orientation of some of the borescope-mapped fractures.

A substantial degree of uncertainty is associated with the possible flow paths shown in Figure 4. The uncertainty is caused by the lack of dyed core samples to match most image anomalies and the fact that borescope data is insufficient to establish which fractures conduct water. Post experiment coreholes were drilled between boreholes 2, 3 , and 4 to locate stained fractures within the measurement plane. This can be observed in Figure 5 where the location of recovered dyed core is compared with an alterant image. Fractures mapped along boreholes $2,3,4$ and along the post-experiment boreholes are also shown (orientation data for the Eractures within the post-experiment boreholes is unavailable; therefore orientation data are not included). Figure 5 shows the range of depths along which the recovered dyed core could have been located. This range of depths is determined by the length of unrecovered core for each corresponding drill run. Figure 5 shows that the location ranges of 3 dyed pieces match the location of 3 image anomalies and that the remaining image anomalies occur along regions where no dyed samples were recovered. Figure 5 also shows that most image anomalies occur where fractures were cetected with the borescope.

The lack of dyed core to match several image anomalies may mean that: a) no tracer flow occurred where image anomalies are present, or b) the drilling process destroyed the evidence. At present, we faver the latter explanation for the following reasons. All of the recovered core was broken into small pieces and some of the core was destroyed by the drilling. Many of the core faces are polished and rounded suggesting grinding; dye could have been destroyed because it only coated fracture surfaces and did not penetrate the matrix of the rock. Furthermore, it is unlikely that the match observed in Figure 4 between image anomalies and fracture location and orientation is accidental. Additional drilling using different equipment is planned to minimize core damage and obtain additional data to continue the evaluation of these results.

In-situ electromagnetic measurements have been performed to evaluate the applicability of alterant geophysical tomography to delineate 
(a)
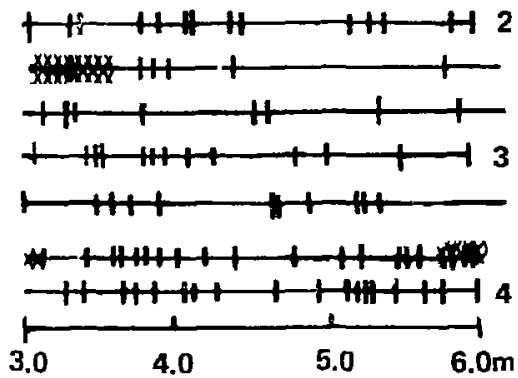

I II I

Fracture locations along boreholes

0000 Dyed fracture locations

(b)

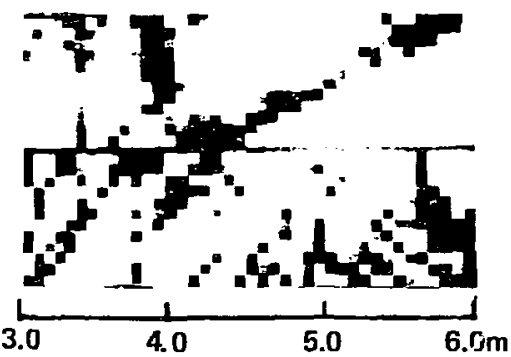

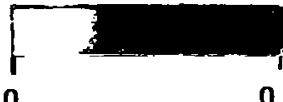

Attenuation rate change $\left(\right.$ meters $\left.^{-1}\right)$

Figure 5. Comparison of an alterant tomograph, fracture location data, and the locations of recovered dyed fractures.

Elow paths in fractured welded tuff. In-situ measurements of electromagnetic attenuation factor at $300 \mathrm{MHz}$ have been made before, during, and after a water based dye tracer flowed through the rock mass. From these data, alterant geotomographs were constructed and tracer flow paths were postulated. The following tentative conclusions can be reached based on evidence available at present.

1. There is indirect evidence suggesting that the tomograph anomalies represent fracture flow. The principal anomalies observed in the alterant tomographs coincide in orientation and location with Eractures mapped by borescope surveys. Generally, mapped fractures can be matched with image anomalies which define lineal trends. The image anomalies changed and, in one case enlarged as tracer flow progressed. Analyses of measurement noise in the alterant images have shown that the major image anomalies observed are caused by factors other than noise.

2. Parts of 3 image anomalies coincide with the location of dyed core, but the remaining anomalies exist where no dyed core was recovered. Either the unverified anomalies are erroneous, or the 
drilling process destroyed the dyed fracture faces. Additional investigations, including coring, are planned to evaluate these possibilities.

3. The borescope logs yielded valuable fracture data which could be correlated with the tomographic data. However, from the borescope data alone, it was difficult to measure fracture orientation accurately and interpolate fractures between boreholes spaced only $30 \mathrm{~cm}$ apart, and it was impossible to tell which fractures would conduct water. Nevertheless, the value of correlating borescope and tomographic data suggests that the two techniques be used together in any at tempt to map water flow in a rock mass.

\section{ACKNOWLEDGMENTS}

The authors are grateful to L. Ballou, R. J. Lytle, F. Heuze, E. F. Laine and $J$. Yow of Lawrence Livermore National Laboratory for helpful advice. This experiment was made possible by the generous cooperation of $R$. Zimmerman and $R$. Schuck from Sandia National Laboratory. This work was funded by the U.S. Department of Energy Nevada Nuclear Waste Storage Investigations. Work performed under the auspices of the U.S. Department of Energy by the Lawrence Livermore National Laboratory under contract number $W-7405-E N G-48$.

\section{REFERENCES}

Daily, W.D. \& A. L. Ramirez 1984. In-situ porosity distribution using geophysical tomography. Geophysical Research Letters. 11 : 614-616.

Johnstone, K. I. \& K. Wolfsberg 1980. Evaluation of tuff as a medium for nuclear waste repository: interim status report on the properties of tuff. Sandia National Laboratory, SAND 80-1464, Albuquerque, New Mexico.

Lager, D. L. \& R. J. Lytle 1977. Determining a subsurface electromagnetic profile from high-frequency measurements by applying reconstruction technique algorithms. Radio Science, 12: 249-260.

Langkopf, B. S. \& E. Eshom 1982. Site exploration for rock mechanics field tests in the Grouse Canyen Member, Belted Range Tuff, Ul2g tunnel complex, Nevada Test Site. Sandia National Laboratory, SAND 81-1897, Albuquerque, New Mexico.

Poley, J. Ph., J. J. Nooteboom \& P. J. deWaal 1978. Use of VHF dielectric measurements for borehole formation analysis. Log Analyst, May-June. 8-30.

Ramirez, A. L. \& R. J. Lytle 1984. Investigation of fracture flow paths using alterant geophysical tomography. Lawrence Livermore National Lahnratory, UCRL-91621, paper submitted to the International Jainnal of Rock Mechanics and Mining Sciences.

Yow, J.L. Waste package environment conceptual test plan for exploratory shaft at Yucca Mountain. Lawrence Livermore National Laboratory, UCID in preparation. 